\title{
Development of functional product enriched with collagen hydrolysate from fish processing waste
}

\author{
Elena Kuprina, ${ }^{1, *}$, Anastasiya Yakkola $^{1}$, Aleksander Kopylov ${ }^{1}$, Maksim Zashikhin ${ }^{1}$, and \\ Aleksandra Kuznetsova ${ }^{1}$ \\ ${ }^{1}$ ITMO University 9, Lomonosov str., St. Petersburg, 191002, Russia
}

\begin{abstract}
Currently, there is an acute issue of environmental pollution and loss of vital substances for the human body and animals - fats, proteins and minerals. Scales, fins, skin, bones, and cartilage are a valuable source for these beneficial substances. The composition of fish protein contains almost all the essential amino acids, which characterizes its high biological value. A large share of the world's catch is underutilized or simply lost, since the fish processing process usually comes down to primary cutting, resulting in a loss of 30 to $70 \%$ of the mass of raw materials in the form of biological waste. Therefore, at present, it is necessary to develop such technologies that will maximize the use of natural raw materials. It was found that the rational, to obtain the highest collagen content in the hydrolyzate, is the double extraction technology, which consists in using the electrochemically obtained hydrolyzate from fish bone waste as an extractant for the isolation of collagen from the skin. In the course of the work, the optimal treatment modes for the cartilage waste from cutting salmon fish by the electrochemical method were determined, as a result of which a protein hydrolyzate was obtained. The technological and physicochemical properties of the obtained protein hydrolyzate are studied, based on which the nutritional and biological value of the product is analyzed.
\end{abstract}

\section{Introduction}

For the normal functioning of the body, for a healthy and fulfilling life, a person needs proteins of collagen nature. They are indispensable in the construction of connective, muscle, bone tissues, for tissue regeneration, for the transfer of oxygen and lipids with blood, as well as for maintaining immunity [1]. The lack or excess of these proteins negatively affects the nutritional balance and human health $[2,3]$.

Nutritionists have established that the physiological need for protein for the adult population is from 65 to $117 \mathrm{~g} /$ day for men and from 58 to $87 \mathrm{~g} /$ day for women, while protein should account for $25-30 \%$ of the daily diet of a healthy adult. The physiological protein requirements of children up to 1 year old are $2.2-2.9 \mathrm{~g} / \mathrm{kg}$ body weight, and children over 1 year old from 36 to $87 \mathrm{~g} /$ day.

\footnotetext{
* Corresponding author: eekuprina@itmo.ru
} 
Collagen is $30 \%$ of the mass of all proteins in the human body. The collagen contained in food is poorly digested in the body in contrast to its hydrolysate. During hydrolysis, the digestibility increases to $90 \%$, this makes it a food and biologically active additive [4]. Collagen restores and supports the human musculoskeletal system [5]. The daily consumption rate is on average $4.5 \mathrm{~g}$.

Fish is an excellent source of collagen protein, which is well absorbed by the human body [6]. The maximum amount of these proteins contains sturgeon, tuna, and red ocean fish. In countries where fish are predominantly consumed, the population is less affected by diseases of the musculoskeletal system [7].

In the process of fish cutting, 30 to $50 \%$ of valuable food-related waste is formed: skin, bones, and fins, which are often thrown away and have a negative cost, polluting the environment [8]. At the same time, many useful substances for the human body and animals are lost - proteins, fats, and minerals [9]. Therefore, at present, special attention is paid to the development of new technologies that allow the maximum use of natural raw materials, expand the range and improve the quality of products. Isolation of collagen from fish skin and its use is an excellent solution to the task of preserving the environment, due to the possibility of creating a waste-free production of fish processing. The absence of toxicity and carcinogenicity makes it possible to speak of the extreme promise of using collagen-containing products as components of functional food, dietary supplements, cosmetic and medical preparations [10].

The concept of a balanced diet influences the solution of problems related to the argumentation of physiological norms of nutrition, the creation of specialized food and diets, the study of new nutrient resources, and the increase in the biological value of popular and generally recognized food [11].

In world practice, the direction of production of products from low-value and nontraditional raw materials enriched with certain vitamins, minerals, dietary fibers, etc. has been determined to provide all groups of the population with the necessary complex of nutrients. Of particular interest in recent years is a raw material of water origin, which has a high nutritional and biological value [12]. It is most convenient to use dispersed raw materials to create functional products. Processing raw fish into minced meat makes it possible to maximize the use of the edible portion of small fish waste and produce a number of fish products, similar to gourmet fish products such as crab, shrimp sticks, etc. It is necessary to increase the efficiency of eating existing fish resources by developing new generation recipes, creating products with a regulated content of proteins, fats, macro- and microelements, vitamins and other important components. A source of enrichment of food products based on minced fish can be a cheap protein filler, a collagen-containing product [13], not inferior to traditional raw materials in terms of nutritional and biological value and increasing the economic feasibility of production and aimed at preventing diseases of the musculoskeletal system in various population groups [14].

The aim of the study was to develop a functional product formulation enriched with collagen hydrolyzate isolated from fish processing waste.

To achieve this goal, it was necessary to study collagen-containing raw materials (fish skin and bones), obtain protein hydrolysate electrochemically from trout skin and bones, study its physical, chemical and technological properties, and evaluate the nutritional and biological value of the functional product produced using the obtained collagen-containing additives.

As objects of study were selected:

1. waste from trout processing-skin and spine bone;

2. collagen-containing product (protein hydrolysate) obtained from fish raw material processing waste by electrochemical method;

3. minced fish (GOST R 55505-2013) 


\section{Research methods}

The amount of total nitrogen and crude protein in protein hydrolysates was determined using the Kjeldahl method using a PertorpAnalytical (Tecator AB) instrument, amine nitrogen in protein concentrates was determined by formol titration, total lipids were determined by weight method after extraction with chloroform in methanol using a dry solvent method. Hydrolysates were determined based on the method for determining water in hydrolysates according to GOST 7636-85.

The amino acid composition of protein concentrates was determined on an LKB 3201 analyzer (Sweden).

The $\mathrm{pH}$ was determined potentiometrically using the I-120.2 ionomer.

The separation of the mineral residue from the protein solution was carried out by the nylon filter.

To extract nutrients from raw materials, the electrolyzer of the original design was used $[15,16]$. The catholyte is an electrochemically activated solution with a $\mathrm{pH}$ value of 9 obtained in the cathode chamber of the electrolyzer by electrolysis of aqueous electrolyte solutions at a current density of $\mathrm{j}=200-400 \mathrm{~A} / \mathrm{m}^{2}$. The raw material dispersed to a particle size of $5 \times 10^{-3} \mathrm{~m}$ was mixed in the reactor with stirrer with the catholyte solution with given hydraulic module. Heating to $65-85{ }^{\circ} \mathrm{C}$ and thermostating was carried out in the reactor with stirrer.

\section{Results and discussion}

To obtain collagen-containing hydrolyzate from the skin and bones of trout, the raw material analysis was carried out. The research results are presented in table1:

Table 1. Physical and chemical composition and degree of protein digestion in waste.

\begin{tabular}{|c|c|c|c|}
\hline \multicolumn{2}{|c|}{ Type of raw material } & Trout skin & Trout bones (with \\
\hline \multirow{2}{*}{ Protein, $\%$} & Collagen & 10.14 & 4.9 \\
\hline & Other proteins & 13.6 & 13.0 \\
\hline \multicolumn{2}{|l|}{ Calx, \% } & 1.6 & 11.8 \\
\hline \multicolumn{2}{|l|}{ Fat, $\%$} & 1.3 & 7.9 \\
\hline \multicolumn{2}{|l|}{ Moisture, \% } & 72,5 & 62,5 \\
\hline \multicolumn{2}{|c|}{ The degree of digestion of proteins, $\%$} & 6.42 & 8.50 \\
\hline
\end{tabular}

Table 1 shows that the bones and skin of salmon fish contain a large amount of fat, which degrades the quality of the product and reduces the shelf life of the target product. Therefore, it is important to provide a fat separation process for its separation in the technology.

Fish skin has a fairly high content of collagen, which is in its natural form and low digestibility of this raw material, so it is necessary to develop an improved technology to improve this indicator.

To improve the electrochemical technology for the production of protein hydrolyzate, the optimal parameters for its production were selected, in which collagen of satisfactory quality is obtained with a high yield, the influence of the type of raw material, $\mathrm{pH}$, redox potential, hydromodule, degree of dispersion, time and temperature of the processes, and the ratio of raw materials: solvent were studied and etc.

During the experiment, it was found that the technology of double extraction is more appropriate ( hydrolyzate from fish bone waste is used as the extractant for the isolation of collagen from the skin). It is likely that the protein from bone waste present in the solution 
functions as a surfactant and promotes the extraction of collagen from the skin in the second stage of processing. Double extraction provides the highest collagen content in the hydrolyzate.

Mineral-containing raw materials (trout backbone) are dispersed to the particle size of $5 * 10^{-3} \mathrm{~m}$, mixed with an extraction solution with a hydromodule of 1:5-7. The mixture is heated for $35-40$ minutes at the temperature of $95 \pm 5^{\circ} \mathrm{C} \mathrm{pH}=12.12$, after which it is divided into a protein concentrate and a mineral precipitate on the filter. Next, the protein solution is processed in the cathode chamber of the electrolyzer for 20 minutes to correct the $\mathrm{pH}$ value. Collagen-containing raw materials (skin) are dispersed to the particle size of $5 * 10^{-3}$ $\mathrm{m}$, mixed with hydrolysate from bones with a hydromodule of 1:5-7. Withstand 30-40 minutes at the temperature of $75 \pm 5^{\circ} \mathrm{C} \mathrm{pH}=11.6$, after which the protein concentrate is obtained by double extraction. The protein concentrate is neutralized with hydrochloric acid to $\mathrm{pH}=7 \pm 0.2$, and (in the case of fatty raw materials) the fat is separated on the separator.

The maximum solubility of bones is $95 \%$.

The maximum solubility of the skin is $98.7 \%$.

The taken ratio of raw materials: extractant $-1: 5-7$, has the advantage that the samples with smaller hydromodules had a relatively small yield of target nutrients, and increasing the hydromodule slightly increases the extraction effect, which makes it unprofitable.

The analysis of physical, chemical and technological properties of the hydrolysate obtained by double extraction methods is carried out. The test results are presented in table 2 and 3 .

Table 2. Physical and chemical properties of hydrolysate obtained by electrochemical double extraction.

\begin{tabular}{|l|c|}
\hline & Collagen-containing hydrolysate \\
\hline Collagen, $\%$ & 45.3 \\
\hline Fat, $\%$ & 0.2 \\
\hline Amount of protein, $\%$ & 54.75 \\
\hline Total nitrogen, $\%$ & 8.76 \\
\hline The degree of digestion of proteins, $\%$ & 93.7 \\
\hline
\end{tabular}

From the data of table 2 it follows that the degree of digestion of proteins has become significantly greater than that of untreated raw materials, from which it follows that the product has high nutritional value.

To determine the use of the obtained protein hydrolyzate, its technological properties were studied, which affect the nutritional value of the product: fat-retaining and emulsifying abilities.

Table 3. Technological properties of hydrolysates obtained by the electrochemical method.

\begin{tabular}{|l|c|c|}
\hline & $\begin{array}{c}\text { The hydrolyzate obtained by the } \\
\text { electrochemical method of double } \\
\text { extraction }\end{array}$ & $\begin{array}{c}\text { The hydrolyzate obtained from } \\
\text { the skin by the electrochemical } \\
\text { method by single extraction }\end{array}$ \\
\hline Fat-emulsifying ability, \% & 80 & 72 \\
\hline Fat- retaining ability, \% & 86 & 77 \\
\hline Foam-forming ability, \% & 8.3 & - \\
\hline $\begin{array}{l}\text { Water- retaining ability } \\
\%\end{array}$ & 82 & - \\
\hline
\end{tabular}


Table 3 shows that collagen hydrolysate obtained by double extraction has good indicators of fat-emulsifying and fat-retaining ability and therefore it is advisable to use it in the production of various pastes, pates, puddings, mayonnaise, sauces, etc.

Due to the high collagen content $(45.3 \%)$, it is reasonable to use the target product as a protein additive in various food products, including minced fish products, in order to improve the functional and technological properties of fish emulsions, their structure and the biological value of the finished product.

In this study, we developed the recipe for the functional food product made from minced fish with the addition of the collagen-containing hydrolysate in order to increase the nutritional and biological value. The results of developing the functional product formulation are presented in table 4.

Table 4. Traditional and enriched with collagen hydrolysate recipe of cutlets.

\begin{tabular}{|c|c|c|}
\hline \multirow{2}{*}{ Recipe Components } & \multicolumn{2}{|c|}{ Mass fraction of the component in the formulation, \% } \\
\cline { 2 - 3 } & Traditional recipe & $\begin{array}{c}\text { Formulation of the functional } \\
\text { product enriched with } \\
\text { collagen hydrolysate }\end{array}$ \\
\hline Minced fish & 60 & 50 \\
\hline Collagen hydrolysate & - & 10 \\
\hline Fresh carrots & 15 & 15 \\
\hline Fresh onion & 9 & 9 \\
\hline Semolina & 5 & 5 \\
\hline Bread crumbs & 6 & 6 \\
\hline Greens (dill/ parsley) & 3 & 1 \\
\hline Common salt & 1 & 1 \\
\hline Ground black pepper & 1 & 100 \\
\hline In total: & 100 & 3 \\
\hline
\end{tabular}

The production scheme is shown in Figure 1.

Collagen hydrolyzate $(5 \%, 10 \%, 15 \%$ and $20 \%$ by weight of minced meat) is added to minced fish thawed at the temperature of $+15^{\circ} \mathrm{C}$ for $10-12$ hours. Then is added clean, peeled, fresh vegetables (carrots and onions), fresh or pre-soaked dry herbs. Next, pour the semolina. Sifted salt and pepper are added in a dry form. Mix the components of the minced meat on a meat mixer until a homogeneous mass is formed, while the temperature of the minced meat should not exceed $14^{\circ} \mathrm{C}$. From the prepared minced meat, oval cutlets are formed, and then breaded. Freeze semi-finished products in freezers to the temperature in the center of the stuffing not higher than minus $10^{\circ} \mathrm{C}$, according to the modes recommended by the current technological instructions.

The best results were shown by the sample containing $10 \%$ hydrolysate. The addition of $10 \%$ collagen hydrolysate ensures that the protein requirement is met by $10 \%$ of the norm in terms of $100 \mathrm{~g}$ of the finished product. Adding more than $10 \%$ of the collagencontaining hydrolysate negatively affects the organoleptic characteristics of the product, which is also associated with the viscosity of the hydrolysate. 


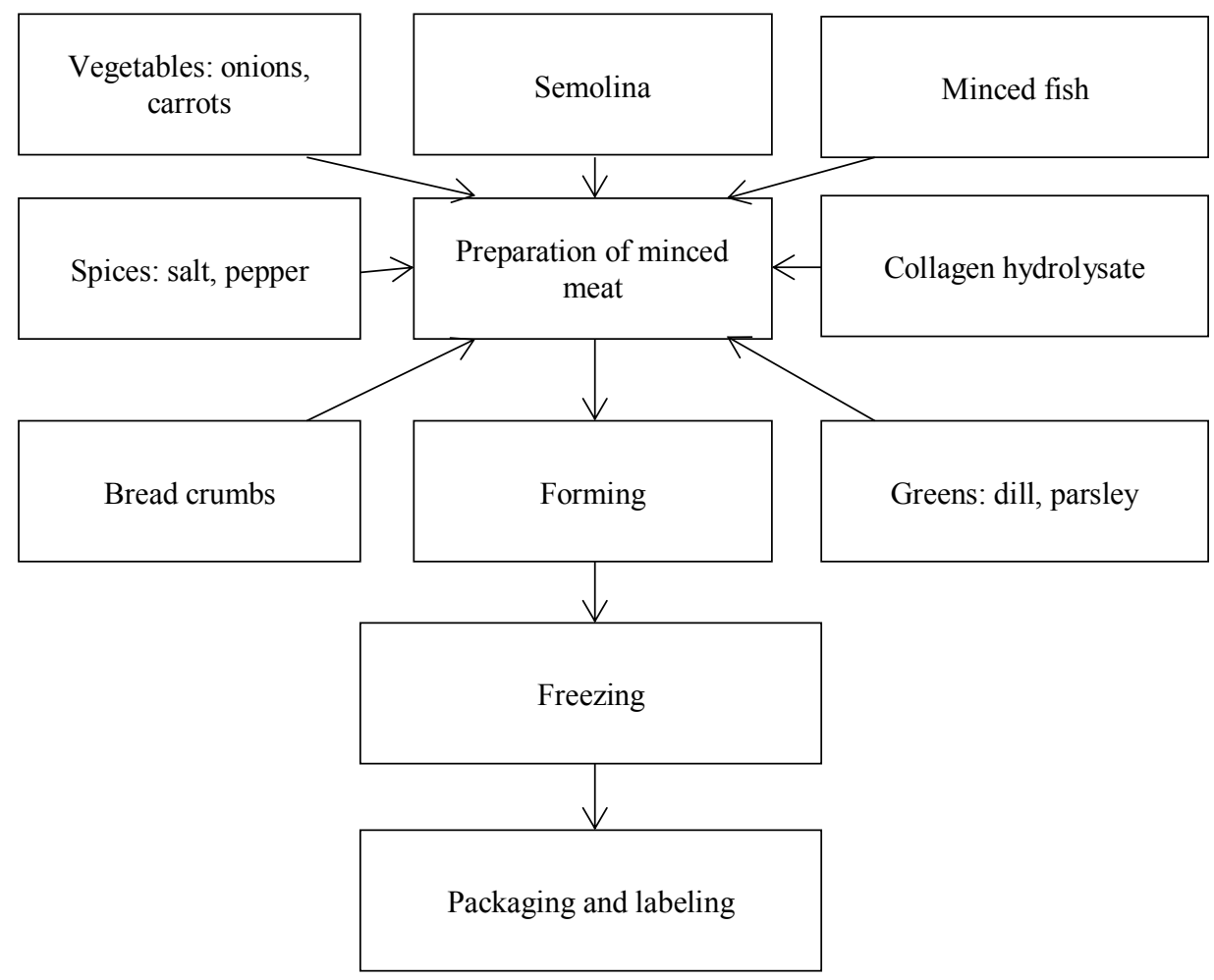

Fig. 1. Block diagram of production of fish cutlets enriched with collagen hydrolysate.

Table 5 shows the organoleptic and physico-chemical parameters of the functional product based on minced fish enriched with collagen hydrolysate.

Table 5. Organoleptic and physico-chemical parameters of the functional product.

\begin{tabular}{|c|c|c|}
\hline \multirow{2}{*}{ Indicator name } & \multicolumn{2}{|r|}{ Indicator value } \\
\hline & Traditional recipe & $\begin{array}{l}\text { Formulation of the functional product } \\
\text { enriched with collagen hydrolysate }\end{array}$ \\
\hline Appearance & \multicolumn{2}{|c|}{ Oval / breading color } \\
\hline Consistency & \multicolumn{2}{|c|}{ Tender, juicy, does not crumble } \\
\hline $\begin{array}{c}\text { Sectional view of } \\
\text { minced meat }\end{array}$ & \multicolumn{2}{|c|}{ Minced meat evenly mixed } \\
\hline Taste and smell & \multicolumn{2}{|c|}{$\begin{array}{l}\text { Characteristic of high-quality raw materials, with the aroma of } \\
\text { onions, without extraneous taste and smell }\end{array}$} \\
\hline \multicolumn{3}{|l|}{ Mass fraction, $\%$ : } \\
\hline Moisture & 58.9 & 61.7 \\
\hline Fat & 17.3 & 18.7 \\
\hline Protein & 12,7 & 16.9 \\
\hline Yield, \% & 82,2 & 85 \\
\hline
\end{tabular}

Such functional product as fish cutlets enriched with the collagen-containing additive is recommended for people suffering from arthritis, arthrosis and osteochondrosis, children, 
the elderly people for the prevention of diseases of the musculoskeletal and cardiovascular systems, for bruises and sprains of ligaments and muscles, for people with problems of the gastrointestinal tract and digestive system.

\section{Conclusions}

The electrochemical parameters for producing the protein hydrolyzate by the double extraction method have been developed; the physicochemical, technological properties and digestibility of the hydrolysates have been studied. The nutritional and biological value of the functional product obtained using extracted collagen-containing additives from salmon processing waste was estimated.

It was found that protein hydrolysate obtained by electrochemical double extraction from fish cutting waste (skin, bones) has improved biochemical and technological parameters, which justifies its use for creating functional food products based on the fish minced meat. The recipe for the fish cutlets was developed, where the collagen-containing hydrolysate obtained by electrochemical method was used as the enriching component.

\section{References}

1. A. J. Cruz-Jentoft, et al., Maturitas 132, 57-64 (2019).

2. D. D. Thomas, et al., Metabolism 79, 83-96 (2018).

3. M. E. J. Lean, Medicine 47(3), 140-144 (2019).

4. D. Dave, et al., Bioresource Technology Reports 7, 100271 (2019).

5. A. Kisling, R. M. Lust, L. C. Katwa, Life sciences 228, 30-34 (2019).

6. N. R. A. Halim, H. M. Yusof, N. M. Sarbon, Trends in Food Science \& Technology 51, 24-33 (2016).

7. K. Hua, et al., One Earth 1(3), 316-329 (2019).

8. M. Atef, S. M. Ojagh, Journal of Functional foods 35, 673-681 (2017).

9. A. Lepeshkin, et al., Agronomy Research 17(6), 2317-2326 (2019).

10. O. Martínez-Alvarez, S. Chamorro, A. Brenes, Food Research International 73, $204-$ 212 (2015).

11. H. Hong, et al., Food chemistry 125222, (2019).

12. E. E. Kuprina, et al., Progress on Chemistry and Application of Chitin and its Derivatives 23, 114-119 (2018).

13. K. O. Lima, et al., Lwt 111, 408-413 (2019).

14. J. García, et al., LWT 109, 55-62 (2019).

15. Utility model: Installation for electrochemical processing of waste from cutting crustaceans Application No. 2019131827/10 (062629), filing date 09.10.2019 MPK A23J1 $\backslash 04$

16. E. E. Kuprina, et al., Progress on Chemistry and Application of Chitin and its Derivatives 24, 96-105 (2019). 